\title{
Role of HER3 expression and PTEN loss in patients with HER2-overexpressing metastatic breast cancer (MBC) who
} received taxane plus trastuzumab treatment

\author{
Y H Park ${ }^{1}$, H A Jung ${ }^{1}$, M K Choi ${ }^{1}$, W Chang ${ }^{1}$, Y L Choi ${ }^{2}$, I-g Do ${ }^{2}$, J S Ahn ${ }^{1}$ and Y-H Im ${ }^{*}, 1$ \\ ${ }^{1}$ Division of Hematology-Oncology, Department of Medicine, Samsung Medical Center, Sungkyunkwan University School of \\ Medicine, Seoul, Korea and ${ }^{2}$ Department of Pathology, Samsung Medical Center, Sungkyunkwan University School of Medicine, \\ Seoul, Korea
}

Background: The aim of this study was to investigate the role of human epidermal growth factor receptor (HER3) and PTEN expression in patients with HER2-overexpressing metastatic breast cancer (MBC).

Methods: One hundred twenty-five MBC patients who were treated with taxane plus trastuzumab chemotherapy as first-line therapy were included in this analysis. Immunohistochemical (IHC) staining with HER3 and PTEN antibodies were conducted retrospectively.

Results: Patients who had negative HER3 staining (62.4\%) had a better progression-free survival (PFS) than did those who had positive HER3 staining ( $P=0.001$; median PFS, 21 vs 11 months). Patients who had a PTEN score $>20$ (78.1\%) showed longer PFS than did those with a PTEN score $\leqslant 20$ ( $P=0.006$; median PFS, 13 vs 9 months). Patients who had a PTEN score $>20$ exhibited a longer overall survival (OS) than did those with a PTEN score $\leqslant 20(P=0.005$; median OS, 48 vs 25 months). HER3 negativity and PTEN loss were identified as independent risk factors for PFS. PTEN loss was identified as an independent risk factor for OS.

Conclusion: HER3 and PTEN expressions may be predictive markers, and PTEN expression may be a predictive and prognostic biomarker for trastuzumab treatment in HER2-positive MBCs.

Trastuzumab, a monoclonal antibody against the human epidermal growth factor receptor 2 (HER2), has changed the treatment paradigm in patients with HER2-positive breast cancer. However, resistance to trastuzumab is an emerging problem and several new HER2-directed strategies have been developed to overcome this resistance (Arteaga et al, 2012; Perez and Spano, 2012). Among the several mechanisms underlying trastuzumab resistance, alteration of the phosphatidylinositol 3-kinase (PI3K)/AKT signalling pathway, which can be activated by HER2, took an early lead in the current translational research in this field (Fabi et al, 2010; Zhang and $\mathrm{Yu}, 2010 ;$ Mukohara, 2011). Trastuzumab has been suggested to inhibit PI3K/AKT survival signalling, either by downregulating
HER2 signalling or by increasing PTEN membrane localisation and phosphatase activity, leading to a decline in the activation of the PI3K/AKT pathway and inhibition of proliferation (Molina et al, 2001; Yakes et al, 2002; Nagata et al, 2004; Berns et al, 2007). In addition, activation of HER-related receptors, such as the HER3 receptor, has been suggested to increase PI3K/AKT signalling, thereby limiting trastuzumab efficacy in preclinical studies (Berns et al, 2007; Sergina et al, 2007). It has also been suggested that $\mathrm{PTEN}$, which is a negative regulator of PI3K/AKT signalling, is involved in tumour sensitivity to trastuzumab. Thus, PTEN loss is negatively correlated with clinical outcomes in patients treated with trastuzumab (Berns et al, 2007). However, the results remain 
contradictory (Barbareschi et al, 2012; Perez and Spano, 2012) and the role of these molecules needs to be determined.

The epidermal growth factor receptor (EGFR) and HER2 classically couple with the Ras-Raf-MEK-mitogen-activated protein kinase (MAPK)-dependent pathway, whereas HER3 is a potent activator of PI3K/AKT (Mosesson and Yarden, 2004; Krause and Van Etten, 2005). It has been shown that the HER2-HER3 heterodimer constitutes the most mitogenic receptor complex within the HER family (Citri et al, 2003). It has also been suggested that this heterodimer is a potent combination in mammary cell line tumorigenesis (Holbro et al, 2003). Several studies have demonstrated that HER3 is frequently co-expressed with HER2 in breast cancer; hence, it is possible that the HER3 receptor has a part in HER2-mediated breast carcinogenesis (Bieche et al, 2003; Witton et al, 2003; Sassen et al, 2008). The prognostic value of HER3 expression in breast cancer has been poorly documented and the available data are not conclusive (Lemoine et al, 1992; Gasparini et al, 1994; Quinn et al, 1994; Travis et al, 1996). Although the overexpression of HER3 has been linked to HER2 positivity (Gasparini et al, 1994) and lymph node involvement (Bieche et al, 2003), a definitive relationship between HER3 and survival has not been established.

On the basis of this background information, we investigated the role of HER3 and PTEN expression in patients with HER2overexpressing metastatic breast cancer (MBC).

\section{MATERIALS AND METHODS}

Patients. Between 2005 and 2011, 125 patients who were at least 20 years of age and were being treated with taxane plus trastuzumab as first-line chemotherapy for histologically confirmed HER2-positive MBC were included in this analysis. HER2 positivity was defined as an intensity of $3+$ by immunohistochemistry (IHC) or as a HER2/centromeric probe for chromosome 17 (CEP17) ratio $>2.0$ by fluorescent in situ hybridisation (Wolff et al, 2007). All patients were required to have an Eastern Cooperative Oncology Group (ECOG) performance status of 0-2 and have available paraffin tissue blocks from metastatic sites or breast tumours for HER3 and PTEN IHC. In addition, patients were eligible if they had received neoadjuvant or adjuvant chemotherapy, including taxanes, anthracyclines, or hormonal therapy, at least 12 months before the onset of taxane plus trastuzumab therapy. Exclusion criteria were previous chemotherapy for MBC, history of neoadjuvant or adjuvant chemotherapy, including trastuzumab or other HER2-directed agents. Thirty-eight patients received a tri-weekly course of paclitaxel plus trastuzumab chemotherapy, and the remaining 87 patients received a triweekly course of docetaxel plus trastuzumab chemotherapy. The triweekly paclitaxel plus trastuzumab regimen consists of the triweekly administration of paclitaxel $\left(175 \mathrm{mg} \mathrm{m}^{-2}\right.$ in bovine serum albumin (BSA)) and trastuzumab at a loading dose of $8 \mathrm{mg} \mathrm{kg}^{-1}$, followed by $6 \mathrm{mg} \mathrm{kg}^{-1}$ every 3 weeks. The triweekly docetaxel plus trastuzumab regimen consists of the administration of docetaxel ( $75 \mathrm{mg} \mathrm{m}^{-2}$ in BSA) every 3 weeks, plus administration of trastuzumab at the same dose as that used in the triweekly paclitaxel plus trastuzumab regimen. This study was approved by the Samsung Medical Center Institutional Review Board.

Acquisition of clinical data. Data regarding patient demographics, pathological classification, treatment response, progression-free survival (PFS), overall survival (OS), and adverse events were obtained retrospectively by reviewing medical records. Treatment response was evaluated using a spiral computed tomography (CT) scan and the Response Evaluation Criteria in Solid Tumors (RECIST) version 1.1 (Eisenhauer et al, 2009).
HER3 and PTEN IHC and measurements. Tissue samples were fixed in buffered $4 \%$ formalin and embedded in paraffin. A slide with a representative tumour was selected, and an area of tumour was circled on the slide.

The standard laboratory protocols were followed for IHC. Antigen retrieval was performed on deparaffinised whole sections $(5 \mu \mathrm{m})$ by using preheated citrate buffer $\left(98^{\circ} \mathrm{C} ; 40 \mathrm{~min}\right)$. Tissue sections were treated with Peroxidase Blocking Reagent (Dako, Carpenteria, CA, USA) and Background Sniper (Biocare, Concord, CA, USA) before manual IHC staining. Slides were incubated with monoclonal antibody against HER3 (mouse monoclonal; M7297, Dako; $1: 100 ; 1 \mathrm{~h}$ at room temperature) and rabbit monoclonal antibody against PTEN (rabbit monoclonal; Cell Signalling, Boston, MA, USA; 1:100; overnight at room temperature). Sections were transferred to a Dako Autostainer Plus (Dako Reference No. S3800) and incubated in secondary antibody (Dako Envision plus Dual Link Horseradish Peroxidase Kit; Dako Reference No. K4061). The high-sensitivity diaminobenzidine (DAB) Chromogenic Substrate System (Betazoid DAB, Biocare) was used for colorimetric visualisation followed by counterstaining with hematoxylin. HER3 staining was categorised by intensity as 0 , $1+, 2+$, and $3+$. Samples with no staining at all, or membrane staining in $<10 \%$ of the tumour cells, result in a score of ' 0 '. A faint or barely perceptible incomplete membrane staining in $>10 \%$ of the tumour cells is scored ' $1+$ '. A weak to moderate staining of the entire membrane in $>10 \%$ of the tumour cells is

\begin{tabular}{|c|c|c|}
\hline \multicolumn{2}{|c|}{ Characteristics } & Values (\%) \\
\hline Age & Median (range) & $48.4(29.9-74.5)$ \\
\hline HER2 status $(N, \%)$ & $\begin{array}{c}\mathrm{IHC}(3+) \\
\mathrm{IHC}(2+) \text { and } \mathrm{FISH}(+)\end{array}$ & $\begin{array}{l}93(74) \\
32(26)\end{array}$ \\
\hline Estrogen receptor status $(N, \%)$ & $\begin{array}{l}\text { Positive } \\
\text { Negative }\end{array}$ & $\begin{array}{l}55(44) \\
70(56)\end{array}$ \\
\hline Progesterone status ( $N, \%)$ & $\begin{array}{l}\text { Positive } \\
\text { Negative }\end{array}$ & $\begin{array}{l}40(32) \\
85(68)\end{array}$ \\
\hline HER3 status $(N, \%)$ & $\begin{array}{l}\text { Positive } \\
\text { Negative }\end{array}$ & $\begin{array}{l}34(30) \\
78(70)\end{array}$ \\
\hline PTEN status $(N, \%)$ & $\begin{array}{c}\text { Positive } \\
\text { Negative (loss) }\end{array}$ & $\begin{array}{l}92(81) \\
22(19)\end{array}$ \\
\hline EGFR $(N, \%)$ & $\begin{array}{l}\text { Positive } \\
\text { Negative }\end{array}$ & $\begin{array}{l}39(48) \\
42(52)\end{array}$ \\
\hline Disease status & $\begin{array}{c}\text { Relapsed } \\
\text { Initially metastatic }\end{array}$ & $\begin{array}{l}81(64.8) \\
44(35.2)\end{array}$ \\
\hline Prior treatments $(N, \%)$ & $\begin{array}{c}\text { Surgery } \\
\text { Neoadjuvant chemotherapy } \\
\text { Adjuvant chemotherapy } \\
\text { Adjuvant radiation therapy }\end{array}$ & $\begin{array}{l}86(68.8) \\
12(9.6) \\
69(55.2) \\
67(53.6)\end{array}$ \\
\hline No. of metastatic sites & $\begin{array}{c}1 \\
2 \\
3 \\
\geqslant 4\end{array}$ & $\begin{array}{c}72(57.6) \\
34(27.2) \\
15(12.0) \\
4(3.2)\end{array}$ \\
\hline Sites of metastasis $(N, \%)$ & $\begin{array}{c}\text { Lymph node } \\
\text { Lung and/or pleura } \\
\text { Liver } \\
\text { Brain } \\
\text { Bone } \\
\text { Others }\end{array}$ & $\begin{array}{c}46(36.8) \\
46(36.8) \\
30(24.0) \\
10(8.0) \\
43(34.4) \\
10(8.0)\end{array}$ \\
\hline ECOG performance status & $\begin{array}{c}0 \text { or } 1 \\
2\end{array}$ & $\begin{array}{l}110(88) \\
15(12)\end{array}$ \\
\hline Treatment regimen & $\begin{array}{c}\text { Triweekly } \\
\text { paclitaxel + trastuzumab } \\
\text { Triweekly } \\
\text { docetaxel + trastuzumab }\end{array}$ & $\begin{array}{l}38(30) \\
87(70)\end{array}$ \\
\hline $\begin{array}{l}\text { Abbreviations: } E C O G=\text { Eastern } \mathrm{Co} \\
\text { factor receptor; HER=human } \\
\text { histochemistry. }\end{array}$ & $\begin{array}{l}\text { erative Oncology Group; EFGR } \\
\text { idermal growth factor recep }\end{array}$ & $\begin{array}{l}=\text { epidermal growth } \\
\text { or; } \quad \mathrm{HC}=\text { immuno }\end{array}$ \\
\hline
\end{tabular}


scored ' $2+$ ' and a strong staining of the entire membrane in $>30 \%$ of the tumour cells results a score of ' $3+$ '. PTEN staining was scored as proportion ( $0-100 \%$ of invasive cells) and intensity $(1+$ to $3+$; weak, moderate, strong) in cytoplasmic staining because there is no validated standard definition for PTEN positivity or loss on the basis of our extensive literature review and personal discussions. The staining in normal elements and stroma was also used as a positive internal assay control, as applicable. The antibody used also produced slight nuclear staining that appeared to reflect in lesser degree the cytoplasmic expression and was of unknown significance.

Additional IHC staining for EGFR (Abcam, Cambridge, UK) was performed in 81 of the cases. Immunohistochemical staining of EGFR was interpreted as 'positive' or 'negative' according to the degree of membrane staining (cutoff value, 10\%).

Statistical analyses. Progression-free survival was measured from the first day of administration of first-line palliative chemotherapy after recurrence to disease progression or death. Overall survival was measured from the day of administration of first-line chemotherapy to death or the final follow-up day. In univariate analysis, independent sample $t$-tests and $\chi^{2}$ tests were used for continuous and categorical variables, respectively. The KaplanMeier product-limit method was used to estimate the PFS and OS. The survival rates were compared using the log-rank test. Multivariate analysis of the independent prognostic factors for survival was performed using the backward stepwise (likelihoodratio statistics based on the conditional parameter estimate) method of the Cox proportional hazard regression model with a 95\% confidence interval (CI). We also incorporated the newly proposed Reporting Recommendations for Tumor Marker Prognostic Studies (REMARK) criteria for tumour marker publications into this study (McShane et al, 2005). As recommended by the REMARK criteria, we included a diagram to describe the descriptive analysis of patient samples performed in this study.

\section{RESULTS}

Patient characteristics. The medical records of $125 \mathrm{MBC}$ patients collected between 2005 and 2011 were analysed for evaluable HER3 and PTEN protein expression. The clinicopathological characteristics of the 125 HER2-positive MBC patients whose tumour blocks were available for HER3 and PTEN IHC are shown in Table 1. The median age of all patients was 48.4 years (range, 29.9-74.5 years). Fifty-five patients $(26 \%)$ were positive for the estrogen receptor (ER) and 40 patients (32\%) were positive for the progesterone receptor. Eighty-one patients $(64.8 \%)$ had recurrent disease after curative treatment, whereas 44 patients (35.2\%) were initially diagnosed with metastatic disease. Eighty-six patients (68.8\%) underwent surgery. Eighty-one patients (64.8\%) received neoadjuvant or adjuvant chemotherapy, and 67 patients (53.6\%) received adjuvant radiotherapy. The sites of metastasis were as follows: lymph node in 46 patients (36.8\%), lung and/or pleura in 46 patients $(36.8 \%)$, liver in 30 patients $(24 \%)$, brain in 10 patients (8\%), and bone in 43 patients (34.4\%). One hundred ten patients $(88 \%)$ had an ECOG performance status of 0 or 1 at the baseline. Treatment regimens were as follows: 38 patients (30\%) received triweekly paclitaxel plus trastuzumab and 87 patients (70\%) received triweekly docetaxel plus trastuzumab. The patients' clinicopathologic characteristics listed by HER3 and PTEN status are shown in Table 2.

HER3 and PTEN expression. HER3 IHC was graded from 0 to $3+$ in membranous staining as described in Materials and Method. As there is no validated standard definition of HER3 positivity and PTEN loss, based on our extensive literature review and personal discussion, we defined it here as follows: HER3 positivity was defined as a grade $>0(1+$ to $3+)$ with at least $1+$ membranous staining. HER3 positivity was shown in $27.2 \%$ of the patients (Figure 1A; Supplementary Figure 1). PTEN IHC was scored as the multiplication of intensity and proportion and ranged from 0 to 300 in cytoplasmic staining. PTEN positivity was defined as a score $>20$ with at least $1+$ cytoplasmic staining. PTEN positivity was found in $78.1 \%$ of patients (Figure 1B). The proportion of patients with concomitant HER3 positivity and PTEN negativity (PTEN loss) was $10.9 \%$ of all patients.

Among 34 patients with HER3-positive disease, 16 (47\%) patients were ER-positive and 8 of $25(32 \%)$ patients with PTEN loss were ER-positive. In addition to these, 4 of 12 (33\%) patients with concomitant HER3-positive disease and PTEN loss were ER-positive.

Table 2. Patients' characteristics according to HER3 and PTEN expression status

\begin{tabular}{|c|c|c|c|c|c|c|}
\hline & HER3 + & HER3 - & $\boldsymbol{P}$-value & PTEN + & PTEN loss & $\boldsymbol{P}$-value \\
\hline ER positivity & $37.2 \%$ & $47.1 \%$ & 0.327 & $39.3 \%$ & $32.0 \%$ & 0.642 \\
\hline EGFR positivity & $42.9 \%$ & $49.1 \%$ & 0.630 & $42.4 \%$ & $75.0 \%$ & 0.026 \\
\hline $\begin{array}{l}\text { Median number of HER2-directed therapy after progression to taxane plus } \\
\text { trastuzumab }\end{array}$ & 1 & 1 & 0.999 & 1 & 2 & 0.425 \\
\hline $\begin{array}{l}\text { Median number of lines of chemotherapy after progression excluding HER2-directed } \\
\text { therapy }\end{array}$ & 8 & 7 & 0.542 & 7 & 6 & 0.424 \\
\hline \multicolumn{7}{|l|}{ Metastatic sites } \\
\hline $\begin{array}{l}\text { Liver } \\
\text { Lung } \\
\text { Brain } \\
\text { Bone } \\
\text { Soft tissue } \\
\text { Skin }\end{array}$ & $\begin{array}{c}5.9 \% \\
20.6 \% \\
21.0 \% \\
26.2 \% \\
0 \% \\
2.9 \%\end{array}$ & $\begin{array}{r}10.3 \% \\
28.2 \% \\
6.1 \% \\
33.2 \% \\
3.8 \% \\
5.1 \%\end{array}$ & $\begin{array}{l}0.721 \\
0.397 \\
0.042 \\
0.423 \\
0.552 \\
0.519\end{array}$ & $\begin{array}{r}7.9 \% \\
24.7 \% \\
14.6 \% \\
30.2 \% \\
2.2 \% \\
4.5 \%\end{array}$ & \begin{tabular}{r|}
$16.0 \%$ \\
$10.0 \%$ \\
$20.0 \%$ \\
$22.4 \%$ \\
$4.0 \%$ \\
$4.0 \%$
\end{tabular} & $\begin{array}{l}0.254 \\
0.792 \\
0.540 \\
0.422 \\
0.528 \\
0.699\end{array}$ \\
\hline \multicolumn{7}{|l|}{ Number of metastatic sites } \\
\hline $\begin{array}{l}1 \\
\geqslant 2\end{array}$ & $\begin{array}{l}42.0 \% \\
68.0 \%\end{array}$ & $\begin{array}{l}75.9 \% \\
24.1 \%\end{array}$ & 0.032 & $\begin{array}{l}89.9 \% \\
10.1 \&\end{array}$ & $\begin{array}{l}88.0 \% \\
12.0 \%\end{array}$ & 0.724 \\
\hline
\end{tabular}


EGFR expression. Thirty-nine of 81 patients who were available for EGFR staining were EGFR-positive (48\%). However, there has been no correlation between HER3 and EGFR positivity $(P=0.63)$. However, the proportion of EGFR-positive patients were found more in PTEN-loss patients than in PTEN-positive patients (75\% vs $42 \%, P=0.026$, Table 2).

Relationship between HER2 expression and metastatic site with number. The patients with HER3 positivity showed more CNS involvement at metastasis than those with HER3 negativity with statistical significance $(21 \%$ vs $6 \%, P=0.042)$. Moreover, the proportion of patients with two or more metastatic sites was higher in HER3-positive than in HER3-negative patients (68.0\% vs $24.1 \%$, $P=0.032$, Table 2).

Prognostic significance of HER3 and PTEN expression including EGFR. During a median follow-up of 36.0 months (range, 12.0-72.5 months), the median PFS and OS of all 125 patients were 12.6 months (95\% CI, 10.0-15.2) and 44.3 months (95\% CI, 36.3-52.6), respectively. The ER-positive patients had better outcomes than did the ER-negative patients in terms of PFS and OS, which are as follows: median PFS, 18.4 vs 10.7 months, $P=0.047$ (Figure 2A); median OS, 63.2 vs 43.4 months, $P=0.016$ (Figure 3A).
The patients who had negative HER3 staining showed a better PFS to taxane plus trastuzumab chemotherapy than did those who had positive HER3 staining $(P=0.001$; median PFS, 20.8 vs 10.5 months; Figure 2B). The patients who had a PTEN score $>20$ exhibited a longer PFS than did those with a PTEN score $\leqslant 20$ ( $P=0.006$; median PFS, 12.6 vs 8.5 months; Figure 2C). The patients who showed negative HER3 staining had a better OS to taxane plus trastuzumab chemotherapy than did those with positive HER3 staining; however, this result was not significant $(P=0.182$; median PFS, 'not reached' vs 43.5 months; Figure $3 \mathrm{~B})$. The patients who had a PTEN score $>20$ showed a longer OS than did those with a PTEN score $\leqslant 20(P=0.005$; median OS, $48.3 v s$ 24.9 months; Figure 3C). The patient who were EGFR-positive had a worse PFS and OS than those who were EGFR-negative (Figures 2D and 3D).

Estrogen receptor negativity, HER3 positivity, and PTEN loss were identified as independent risk factors for PFS in a multivariate Cox-regression model $(\mathrm{HR}=1.67$ (95\% CI, 1.06-2.64), $P=0.027$ for $\mathrm{ER}$ negativity; $\mathrm{HR}=2.43$ (95\% CI, 1.38-4.28), $P=0.002$ for HER3 negativity; and $\mathrm{HR}=2.1$ (95\% CI, 1.2-3.7), $P=0.007$ for PTEN loss). However, ER negativity and PTEN loss $(\mathrm{HR}=1.95(95 \% \mathrm{CI}, 1.01-3.78), P=0.048$ for $\mathrm{ER}$ negativity;

\section{A}

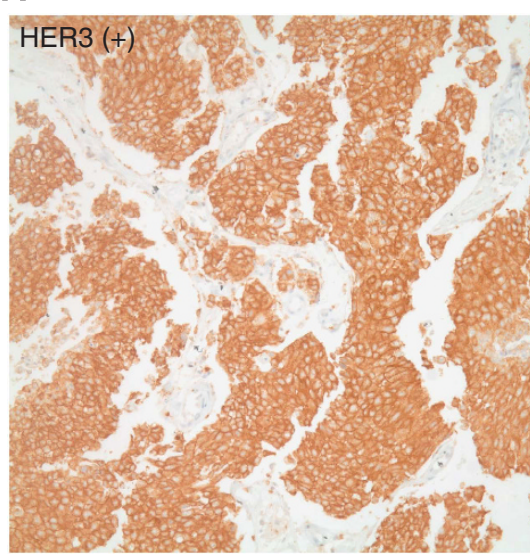

The tumour cells show diffuse strong membranous staining of HER3 (x200)

\section{B}

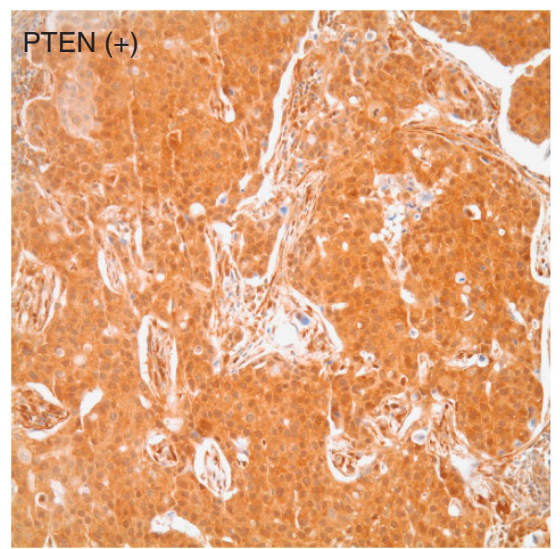

The tumour cells show diffuse strong cytoplasmic staining of PTEN (x200)

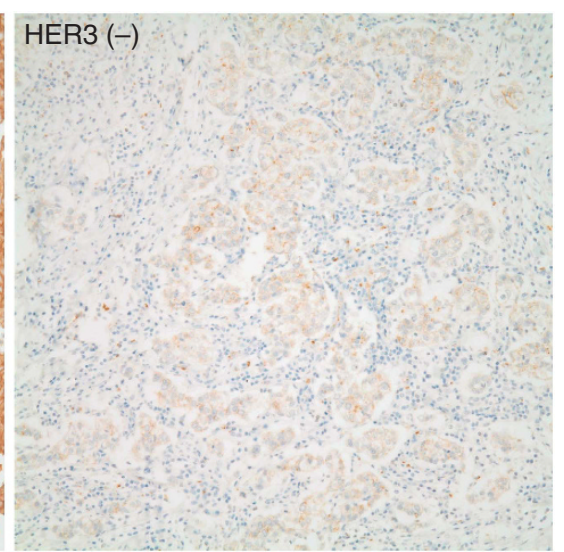

\section{.}




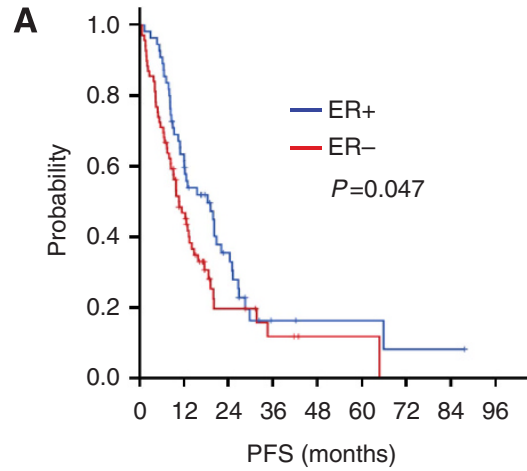

No. at risk

$$
\begin{array}{rrrrrrrrrr}
- & 55 & 33 & 13 & 3 & 2 & 1 & 0 & 0 & 0 \\
- & 70 & 28 & 7 & 3 & 1 & 1 & 0 & 0 & 0
\end{array}
$$

C

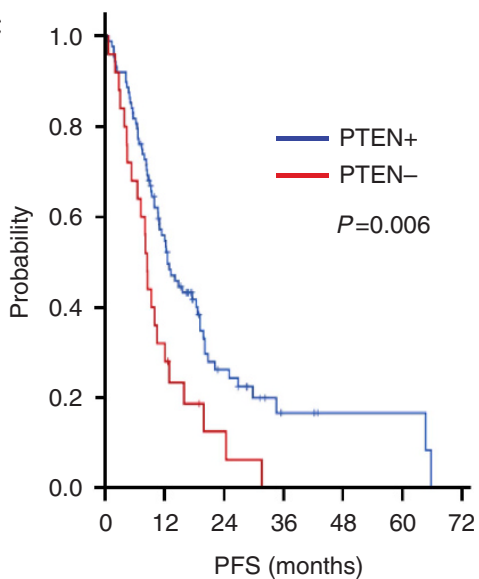

No. at risk

$$
\begin{array}{rrrrrrr}
-87 & 45 & 14 & 4 & 2 & 2 & 0 \\
-24 & 8 & 2 & 0 & 0 & 0 & 0
\end{array}
$$

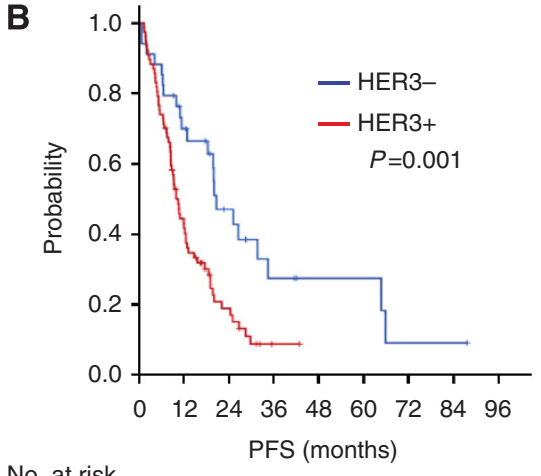

No. at risk

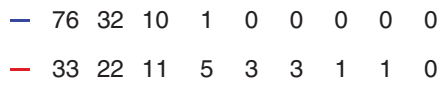

D

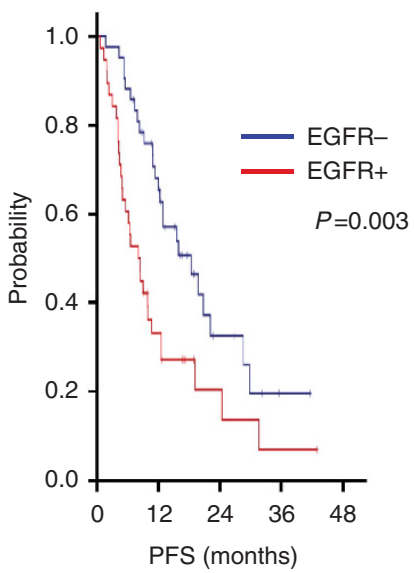

No. at risk

$\begin{array}{rrrrr}-41 & 26 & 6 & 1 & 0 \\ -\quad 38 & 11 & 3 & 1 & 0\end{array}$

Figure 2. Kaplan-Meier PFS curves according to IHC. (A) PFS according to ER status. (B) PFS according to HER3 status. (C) PFS according to PTEN status. (D) PFS according to EGFR status.

$\mathrm{HR}=1.56(95 \% \mathrm{CI}, 0.72-3.37), P=0.256$ for HER3 positivity; and $\mathrm{HR}=3.2 \quad$ (95\% CI, 1.6-6.5), $P=0.001$ for PTEN loss) were identified as an independent risk factor for OS (Table 3). In multivariate analysis, EGFR was not included because of small number of patients.

To evaluate HER3 positivity plus PTEN loss in HER2overexpressing MBC patients, a log-rank test for Kaplan-Meier PFS and OS was performed. Patients with HER3 positivity plus PTEN loss had worse PFS and OS than did the remaining patients (median PFS, 6.5 vs 13.0 months, $P=0.001$; median OS, 23.1 vs 48.3 months, $P=0.002$, Figures $4 \mathrm{~A}$ and $\mathrm{B}$ ).

\section{DISCUSSION}

Despite the remarkable advancement in the treatment of HER2overexpressing breast cancer provided by anti-HER2-directed therapy, especially trastuzumab, treatment resistance remains a main problem that needs to be solved. Among the few key mechanisms that underlie this phenomenon, signalling by other HER-family members, including HER3, and hyperactivation of the PI3K pathway associated with PTEN loss have been suggested to be the main causes of trastuzumab resistance (Yarden and Sliwkowski, 2001; Nahta et al, 2006). PTEN loss in tumours leads to a lack in negative regulation of PI3K signalling and aberrant activation of the transforming pathway. Thus, this regulation is particularly important in HER2-overexpressing breast cancer, which relies on HER2-activated PI3K for progression and survival (Yakes et al, 2002; Junttila et al, 2009). Furthermore, HER3 contains six PI3Kbinding sites, which places the HER2-HER3 heterodimers among the most potent activators of the PI3K pathway (Holbro et al, 2003; Chan et al, 2005).

Surprisingly, one report showed no impact of PTEN loss in a large prospective adjuvant cohort (N9831 trial) (Perez et al, 2013). Those authors defined PTEN positivity as any staining of $>0 \%$. According to their results, the patients with HER2-positive early breast cancer with or without PTEN benefited from adjuvant trastuzumab. However, our data showed that PTEN loss resulted in worse outcomes in terms of PFS and OS in a cohort with metastatic cancer treated with taxane plus trastuzumab as the first-line treatment. These results were consistent with several PTEN-related results (Nagata et al, 2004; Fujita et al, 2006; Esteva et al, 2010; Razis et al, 2011). Although there are some plausible explanations for this discrepancy, metastatic retrospective cohort, IHC, and null PTEN with other aberrations in the PI3K pathway, more relevant clinical data are needed to evaluate this issue. In addition, our data suggest a role for the assessment of the concomitant expression of HER3 and PTEN loss using IHC in this clinical setting as a predictive biomarker of trastuzumab treatment. It is important to 

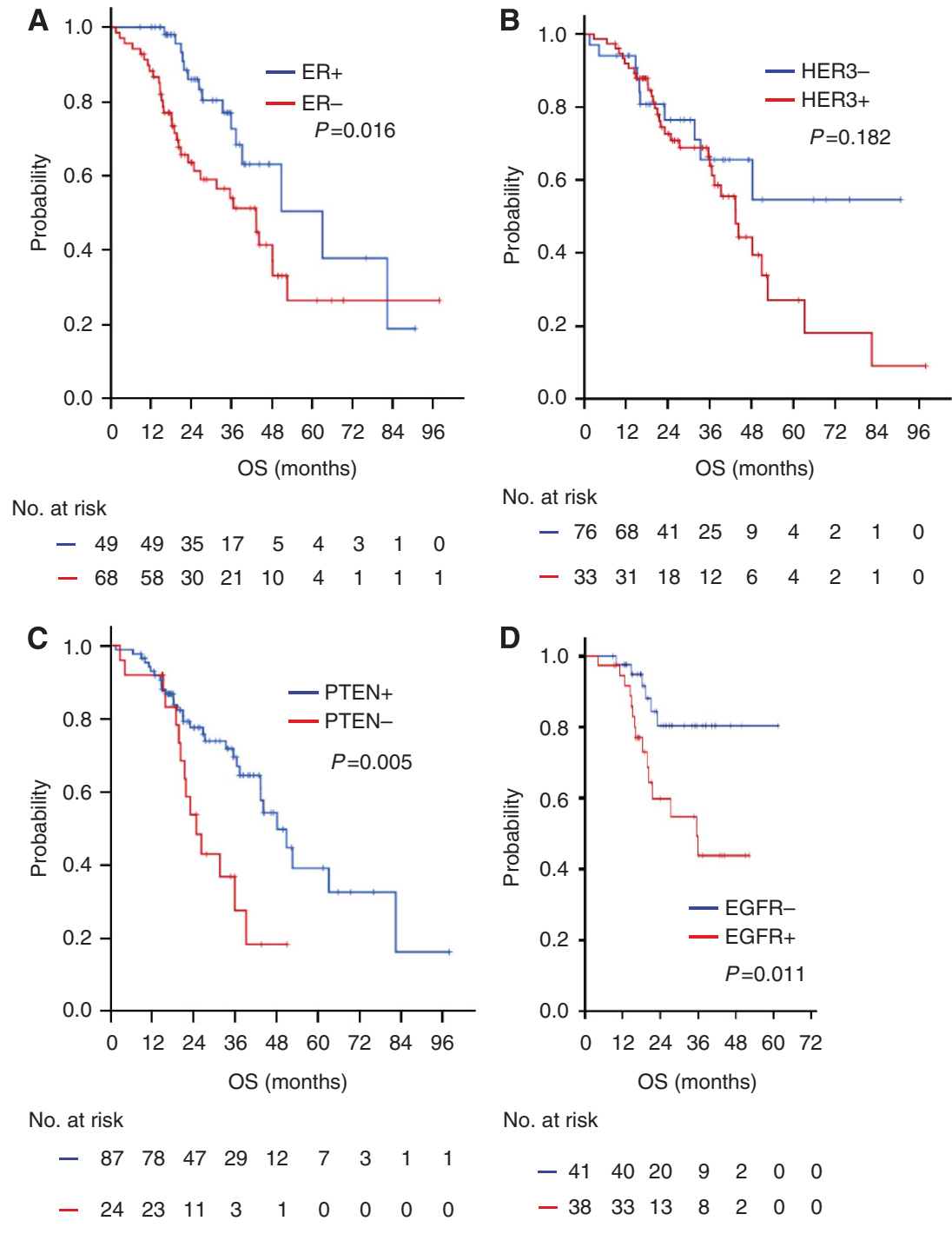

No. at risk

$$
\begin{array}{lllllll}
-41 & 40 & 20 & 9 & 2 & 0 & 0 \\
-38 & 33 & 13 & 8 & 2 & 0 & 0
\end{array}
$$

Figure 3. Kaplan-Meier OS curves according to IHC. (A) OS according to ER status. (B) OS according to HER3 status. (C) OS according to PTEN status. (D) OS according to EGFR status.

\begin{tabular}{|c|c|c|c|c|c|c|}
\hline & \multicolumn{3}{|c|}{ PFS } & \multicolumn{3}{|c|}{ os } \\
\hline & Hazard ratio & $95 \% \mathrm{Cl}$ & $\boldsymbol{P}$-value & Hazard ratio & $95 \% \mathrm{Cl}$ & $\boldsymbol{P}$-value \\
\hline ER negativity & 1.674 & $1.061-2.642$ & 0.027 & 1.950 & $1.007-3.776$ & 0.048 \\
\hline HER3 positivity & 2.428 & $1.376-4.283$ & 0.002 & 1.561 & $0.724-3.366$ & 0.256 \\
\hline PTEN loss & 2.124 & $1.224-3.686$ & 0.007 & 3.190 & $1.576-6.458$ & 0.001 \\
\hline
\end{tabular}

Table 3. Cox-regression multivariate analysis for PFS and OS

note that some patients who exhibited concomitant expression of HER3 and PTEN loss might have worse clinical outcomes to taxane plus trastuzumab treatment compared with other patients. Concomitant expression of HER3 and PTEN loss was present in $10.9 \%$ of all patients included in our cohort. This finding suggests that concomitant expression of HER3 and PTEN loss may explain the primary resistance to trastuzumab treatment in specific populations of cancer patients. Therefore, one of the strengths of our study was the demonstration of the clinical implications of the concomitant expression of HER3 and PTEN loss. In contrast, it also had a major limitation-that is, retrospective design based on a small-sized cohort of metastatic patients.

Taken together, these data suggest that PTEN loss and HER3 positivity, as assessed using IHC, might be surrogate markers that can be used to predict outcomes to taxane plus trastuzumab treatment in patients with HER2-overexpressing 

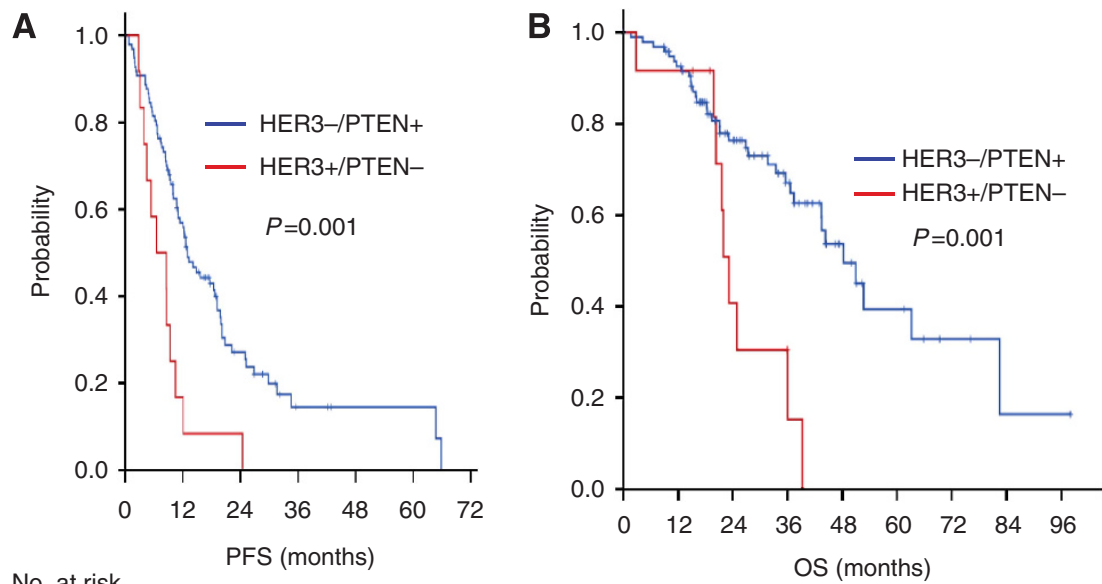

No. at risk

No. at risk

\begin{tabular}{|c|c|c|c|c|c|}
\hline-97 & 51 & 16 & 4 & 2 & 2 \\
\hline-11 & 2 & 1 & 0 & 0 & 0 \\
\hline
\end{tabular}

$\begin{array}{rrrrrrrrr}-97 & 86 & 51 & 31 & 13 & 7 & 3 & 1 & 1 \\ -11 & 11 & 4 & 1 & 0 & 0 & 0 & 0 & 0\end{array}$

Figure 4. Kaplan-Meier PFS and OS curves. (A) PFS between the patients with HER3 - /PTEN + and those with HER3 + /PTEN loss. (B) OS between the patients with HER3 - /PTEN + and those with HER3 + /PTEN loss.

MBC. A validation study of a comprehensive set of genetic aberrations in the PI3K pathway is warranted.

\section{CONFLICT OF INTEREST}

The authors declare no conflict of interest.

\section{REFERENCES}

Arteaga CL, Sliwkowski MX, Osborne CK, Perez EA, Puglisi F, Gianni L (2012) Treatment of HER2-positive breast cancer: current status and future perspectives. Nat Rev Clin Oncol 9: 16-32.

Barbareschi M, Cuorvo LV, Girlando S, Bragantini E, Eccher C, Leonardi E, Ferro A, Caldara A, Triolo R, Cantaloni C, Decarli N, Galligioni E, Dalla Palma P (2012) PI3KCA mutations and/or PTEN loss in Her2-positive breast carcinomas treated with trastuzumab are not related to resistance to anti-Her2 therapy. Virchows Arch 461: 129-139.

Berns K, Horlings HM, Hennessy BT, Madiredjo M, Hijmans EM, Beelen K, Linn SC, Gonzalez-Angulo AM, Stemke-Hale K, Hauptmann M, Beijersbergen RL, Mills GB, van de Vijver MJ, Bernards R (2007) A functional genetic approach identifies the PI3K pathway as a major determinant of trastuzumab resistance in breast cancer. Cancer Cell 12: 395-402.

Bieche I, Onody P, Tozlu S, Driouch K, Vidaud M, Lidereau R (2003) Prognostic value of ERBB family mRNA expression in breast carcinomas. Int J Cancer 106: 758-765.

Chan CT, Metz MZ, Kane SE (2005) Differential sensitivities of trastuzumab (Herceptin)-resistant human breast cancer cells to phosphoinositide-3 kinase (PI-3K) and epidermal growth factor receptor (EGFR) kinase inhibitors. Breast Cancer Res Treat 91: 187-201.

Citri A, Skaria KB, Yarden Y (2003) The deaf and the dumb: the biology of ErbB-2 and ErbB-3. Exp Cell Res 284: 54-65.

Eisenhauer EA, Therasse P, Bogaerts J, Schwartz LH, Sargent D, Ford R, Dancey J, Arbuck S, Gwyther S, Mooney M, Rubinstein L, Shankar L, Dodd L, Kaplan R, Lacombe D, Verweij J (2009) New response evaluation criteria in solid tumours: revised RECIST guideline (version 1.1). Eur J Cancer 45: 228-247.

Esteva FJ, Guo H, Zhang S, Santa-Maria C, Stone S, Lanchbury JS, Sahin AA, Hortobagyi GN, Yu D (2010) PTEN, PIK3CA, p-AKT, and p-p70S6K status: association with trastuzumab response and survival in patients with HER2-positive metastatic breast cancer. Am J Pathol 177: 1647-1656.

Fabi A, Metro G, Di Benedetto A, Nistico C, Vici P, Melucci E, Antoniani B, Perracchio L, Sperduti I, Milella M, Cognetti F, Mottolese M (2010) Clinical significance of PTEN and p-Akt co-expression in HER2-positive metastatic breast cancer patients treated with trastuzumab-based therapies. Oncology 78: 141-149.

Fujita T, Doihara H, Kawasaki K, Takabatake D, Takahashi H, Washio K, Tsukuda K, Ogasawara Y, Shimizu N (2006) PTEN activity could be a predictive marker of trastuzumab efficacy in the treatment of ErbB2-overexpressing breast cancer. Br J Cancer 94: 247-252.

Gasparini G, Gullick WJ, Maluta S, Dalla Palma P, Caffo O, Leonardi E, Boracchi P, Pozza F, Lemoine NR, Bevilacqua P (1994) c-erbB-3 and c-erbB-2 protein expression in node-negative breast carcinoma-an immunocytochemical study. Eur J Cancer 30A: 16-22.

Holbro T, Beerli RR, Maurer F, Koziczak M, Barbas 3rd CF, Hynes NE (2003) The ErbB2/ErbB3 heterodimer functions as an oncogenic unit: ErbB2 requires ErbB3 to drive breast tumor cell proliferation. Proc Natl Acad Sci USA 100: 8933-8938.

Junttila TT, Akita RW, Parsons K, Fields C, Lewis Phillips GD, Friedman LS, Sampath D, Sliwkowski MX (2009) Ligand-independent HER2/HER3/ PI3K complex is disrupted by trastuzumab and is effectively inhibited by the PI3K inhibitor GDC-0941. Cancer Cell 15: 429-440.

Krause DS, Van Etten RA (2005) Tyrosine kinases as targets for cancer therapy. N Engl J Med 353: 172-187.

Lemoine NR, Barnes DM, Hollywood DP, Hughes CM, Smith P, Dublin E, Prigent SA, Gullick WJ, Hurst HC (1992) Expression of the ERBB3 gene product in breast cancer. Br J Cancer 66: 1116-1121.

McShane LM, Altman DG, Sauerbrei W, Taube SE, Gion M, Clark GM (2005) Reporting recommendations for tumor marker prognostic studies (REMARK). J Natl Cancer Inst 97: 1180-1184.

Molina MA, Codony-Servat J, Albanell J, Rojo F, Arribas J, Baselga J (2001) Trastuzumab (herceptin), a humanized anti-Her2 receptor monoclonal antibody, inhibits basal and activated Her2 ectodomain cleavage in breast cancer cells. Cancer Res 61: 4744-4749.

Mosesson Y, Yarden Y (2004) Oncogenic growth factor receptors: implications for signal transduction therapy. Semin Cancer Biol 14: 262-270.

Mukohara T (2011) Mechanisms of resistance to anti-human epidermal growth factor receptor 2 agents in breast cancer. Cancer Sci 102: 1-8.

Nagata Y, Lan KH, Zhou X, Tan M, Esteva FJ, Sahin AA, Klos KS, Li P, Monia BP, Nguyen NT, Hortobagyi GN, Hung MC, Yu D (2004) PTEN activation contributes to tumor inhibition by trastuzumab, and loss of PTEN predicts trastuzumab resistance in patients. Cancer Cell 6: 117-127.

Nahta R, Yu D, Hung MC, Hortobagyi GN, Esteva FJ (2006) Mechanisms of disease: understanding resistance to HER2-targeted therapy in human breast cancer. Nat Clin Pract Oncol 3: 269-280.

Perez EA, Dueck AC, McCullough AE, Chen B, Geiger XJ, Jenkins RB, Lingle WL, Davidson NE, Martino S, Kaufman PA, Kutteh LA, Sledge GW, Harris LN, Gralow JR, Reinholz MM (2013) Impact of PTEN protein expression on benefit from adjuvant trastuzumab in early-stage human epidermal growth factor receptor 2-positive breast cancer in the North Central Cancer Treatment Group N9831 trial. J Clin Oncol 31: 2115-2122. 
Perez EA, Spano JP (2012) Current and emerging targeted therapies for metastatic breast cancer. Cancer 118: 3014-3025.

Quinn CM, Ostrowski JL, Lane SA, Loney DP, Teasdale J, Benson FA (1994) c-erbB-3 protein expression in human breast cancer: comparison with other tumour variables and survival. Histopathology 25: $247-252$.

Razis E, Bobos M, Kotoula V, Eleftheraki AG, Kalofonos HP, Pavlakis K, Papakostas P, Aravantinos G, Rigakos G, Efstratiou I, Petraki K, Bafaloukos D, Kostopoulos I, Pectasides D, Kalogeras KT, Skarlos D, Fountzilas G (2011) Evaluation of the association of PIK3CA mutations and PTEN loss with efficacy of trastuzumab therapy in metastatic breast cancer. Breast Cancer Res Treat 128: 447-456.

Sassen A, Rochon J, Wild P, Hartmann A, Hofstaedter F, Schwarz S, Brockhoff G (2008) Cytogenetic analysis of HER1/EGFR, HER2, HER3 and HER4 in 278 breast cancer patients. Breast Cancer Res 10: R2.

Sergina NV, Rausch M, Wang D, Blair J, Hann B, Shokat KM, Moasser MM (2007) Escape from HER-family tyrosine kinase inhibitor therapy by the kinase-inactive HER3. Nature 445: 437-441.

Travis A, Pinder SE, Robertson JF, Bell JA, Wencyk P, Gullick WJ, Nicholson RI, Poller DN, Blamey RW, Elston CW, Ellis IO (1996) C-erbB-3 in human breast carcinoma: expression and relation to prognosis and established prognostic indicators. Br J Cancer 74: 229-233.
Witton CJ, Reeves JR, Going JJ, Cooke TG, Bartlett JM (2003) Expression of the HER1-4 family of receptor tyrosine kinases in breast cancer. J Pathol 200: 290-297.

Wolff AC, Hammond ME, Schwartz JN, Hagerty KL, Allred DC, Cote RJ, Dowsett M, Fitzgibbons PL, Hanna WM, Langer A, McShane LM, Paik S, Pegram MD, Perez EA, Press MF, Rhodes A, Sturgeon C, Taube SE, Tubbs R, Vance GH, van de Vijver M, Wheeler TM, Hayes DF (2007) American Society of Clinical Oncology/College of American Pathologists guideline recommendations for human epidermal growth factor receptor 2 testing in breast cancer. J Clin Oncol 25: 118-145.

Yakes FM, Chinratanalab W, Ritter CA, King W, Seelig S, Arteaga CL (2002) Herceptin-induced inhibition of phosphatidylinositol-3 kinase and Akt Is required for antibody-mediated effects on p27, cyclin D1, and antitumor action. Cancer Res 62: 4132-4141.

Yarden Y, Sliwkowski MX (2001) Untangling the ErbB signalling network. Nat Rev Mol Cell Biol 2: 127-137.

Zhang S, Yu D (2010) PI(3)king apart PTEN's role in cancer. Clin Cancer Res 16: 4325-4330.

This work is published under the standard license to publish agreement. After 12 months the work will become freely available and the license terms will switch to a Creative Commons AttributionNonCommercial-Share Alike 3.0 Unported License.

Supplementary Information accompanies this paper on British Journal of Cancer website (http://www.nature.com/bjc) 